\title{
Strategic Sourcing for Entry \\ Deterrence and Tacit Collusion
}

\author{
YUTian CheN*
}

February 2, 2010

\begin{abstract}
By sourcing key intermediate goods to a potential entrant, incumbent firm can credibly and observably commit to an intense post-entry competition, thereby deter the entrant's entry. At the same time, a tacit collusion exists, and the entrant's loss from staying out of the final-good market is compensated through their sourcing transaction. We find that, there exist scenarios where entry-deterring sourcing enhances not only social welfare but also consumers' welfare, although in general it has ambiguous effect on social welfare.
\end{abstract}

Keywords: Sourcing; Entry deterrence; Stackelberg Competition; Cournot Competition JEL Classification: D41, L11, L13

*Department of Economics, California State University, Long Beach, CA 90840, USA. Email: ychen7@csulb.edu; Tel: 562-985-5083; Fax: 562-985-5804 


\section{Introduction}

While firms invariably endeavor to minimize their input cost when they configure the supply of critical intermediate goods, literature reveals many strategic elements which may play a pivotal role in firms' sourcing decisions. In this work, we show that sourcing strategy can be utilized for entry deterrence and tacit collusion. An incumbent firm, by sourcing key intermediate goods to a potential entrant, can deter the entrant from producing the final good. At the same time, a tacit collusion exists, and both firms can be better off in their sourcing relationship compared to the autarky situation. We find that, strategic considerations can dominate cost minimization, leading the incumbent to source to the entrant when the entrant is costlier than the incumbent with the intermediate goods production.

There are sourcing practices in the business world which could be anticompetitive. In the aircraft industry, one observation is about Boeing and a Japanese consortium composed of the three biggest industrial giants of Japan: Mitsubishi Heavy Industries, Kawasaki Heavy Industries LTD, and Fuji Heavy Industries. These Japanese firms expressed an interest in entering the market for commercial aircrafts. Consequently, agreements were signed between Boeing and the Japanese firms. According to the agreements, Boeing would purchase from them the 767-X fuselage during the 1990s (Chicago Tribune, April 14, 1990), and then wings, together with related research and development during the 2000s (Chicago Tribune, December 21, 2003). Boeing's outsourcing cannot be easily justified based on cost-saving, since in the airline industry, costs in Japan "are just as high as or higher than at home" (Newsweek International Edition, May 15-22, 2006). Another observation is about Boeing and Lockheed. Although Lockheed exited the commercial aircraft market after 1981, it still possessed the production capability to reenter and compete with Boeing. Boeing signed a contract with Lockheed to purchase from Lockheed certain parts of commercial aircraft (The Wall Street Journal, May 10, 1989, p. 87). Subsequently, Lockheed never reentered the commercial aircraft market.

To investigate strategic considerations underlying such sourcing practices, we analyze a simple model with an incumbent and an entrant for a final good. An intermediate good is required in order to produce the final good. The incumbent can produce both the intermediate good and the final good, whereas the entrant can only produce the intermediate good. By making some irreversible investment, the entrant can be equally efficient as the incumbent in producing the final good. To abstract from other determinants of sourcing, we assume that the incumbent is more efficient than the entrant in producing the intermediate good. These two firms interact in a three-stage game. In stage one, the incumbent's sourcing strategy for the intermediate good is determined. If the incumbent outsources to the entrant, the entrant gets informed with the quantity it is obligated to supply. In stage two, the entrant makes its entry decision. In stage three, they engage in quantity competition if the entrant enters to produce the final good.

We find that, the model has a unique equilibrium in terms of the sourcing strategy. It can occur in equilibrium that the incumbent sources certain quantity of the intermediate good to the entrant. As a consequence, the entrant stays out of the final good market.

The effect of sourcing from the incumbent to the entrant is two-fold. On the one side, the outsourced quantity constitutes a "capacity" for the incumbent before entry occurs. When producing within the established capacity, the incumbent is granted a Stackelberg leader's advantage and is bent on taking a more aggressive response towards entry. The entrant, 
understanding that the incumbent will fully convert its acquired intermediate good into the final good, is forced into a Stackelberg follower after its entry. Consequently, it has less incentive to practice entry. As such, by ordering no less than some threshold quantity from the entrant, the incumbent is able to keep the entrant out of the final good market. On the other side, outsourcing leads to a tacit collusion. With the entrant's entry deterred, the final good market is kept monopolized and the entry cost is avoided. Whenever the benefit of outsourcing is more than offsetting its cost, a joint surplus is generated and both firms can be better off through their sourcing transaction.

Two conditions are required for the entry-deterring outsourcing to arise in equilibrium. First, the entrant's cost disadvantage can not be too substantial, otherwise outsourcing involves a big efficiency loss and becomes suboptimal. Second, the entry cost can not be too small. If not, deterring entry requires the incumbent to outsource a huge quantity in order to commit to an aggressive enough stance upon entry. Such a huge quantity leads to a low profit in the final good market, making outsourcing unprofitable.

Although entry-deterring outsourcing implies a monopolized final-good market together with efficiency loss, it does not necessarily reduce social welfare. In fact, outsourcing can improve social welfare either due to a large entry cost saved, or due to a large quantity produced for the final good. The latter case occurs when the entrant faces a relatively small entry cost, which gives the entrant a strong incentive to enter. Thus for entry deterrence, the incumbent needs to commit to a quantity not too small. As a result, consumers' loss is moderate and can be dominated by the gain of firms, resulting in an enhanced social welfare. In fact, the aggressive stance taken by the incumbent can even benefit consumers. If the entry cost is very small hence deterring entry requires a quantity exceeding the duopoly quantity, consumers are benefited by entry-deterring outsourcing.

We do not impose exclusivity on the incumbent's make-or-buy decision. In our model, the incumbent can always outsource as well as produce the intermediate good in-house. We find that, whenever outsourcing occurs, for relatively small entry cost, the incumbent outsources exclusively to the entrant without any in-house production. Instead, for relatively large entry cost, there is a mixture in the incumbent's sourcing strategy: the incumbent outsources exactly the threshold quantity needed for entry deterrence, and produces in-house the remainder of its demand.

Our finding indicates that, everything else being equal, providers who pose a real entry threat are less likely to practice entry compared to entrants who are independent of the incumbent. It thus offers insight for a puzzling empirical finding, as shown below. Literature points out that there are good reasons for firms to beware of the entry potential of their key suppliers. Caves and Porter (1977) argue that, "important suppliers to an industry ... are often likely entry candidates". ${ }^{1}$ However, empirical findings tell quite a different story. Smiley (1988) summarizes an extensive survey across a broad range of industries regarding what source of entry concerns them the most. One finding is, "surprisingly few firms were concerned about new entrants ...from (among) their suppliers". This finding is consistent with an arising trend nowadays that firms outsource their "core" activities including R\&D

\footnotetext{
${ }^{1}$ As listed out in Caves and Porter (1977), suppliers are likely to possess key elements for a successful entry, including well-established distribution or service networks, and the ability to produce components transformable into other commodities. One can also name other reasons for key suppliers to be likely entrant candidates. For example, it could be relatively easier for providers to infer information regarding the downstream market demand or consumers' tastes.
} 
in disregard of the potential that their providers might turn into fierce competitors. For example, pharmaceutical giants such as GlaxoSmithKline and Eli Lilly outsource to Asian bio-tech research companies for bringing new drug to market; Dell, Motorola and Philips are buying complete designs of some digital devices from Asian developers, although "there is a lot of great capability that has grown in Asia to develop complete products" (BusinessWeek, March 21, 2005). While other factors could be at play, our work highlights that, the buyerseller relationship offers a channel of implicit collusion. As a result, suppliers could be less inclined to enter and compete compared to independent entrants.

The rest of the paper is organized as follows. Section 2 review the related literature. Section 3 gives our benchmark model and main result. Model analysis including more intuition to our result is in Section 4. Section 5 discusses our result by considering several model variations. Section 6 then concludes.

\section{Related Literature}

Our work is in line with literature where incumbent builds entry-deterring capacity to secure monopoly profit (Spence (1977), Dixit (1979, 1980)). An easy-to-see difference between outsourcing and capacity-building in entry deterrence is that, there is no tacit collusion when the incumbent builds up capacity for entry deterrence, and the entrant is a passive player there. More implicitly, capacity built by the incumbent suffers observability problems and may totally lose its value in entry deterrence, as pointed out in previous literature (see Bagwell (1995) and Várdy (2004)). Whereas, such observability problems are unlikely to arise with outsourcing to deter the entrant's entry. More comparison of these two strategies is given in Section 5 .

Our work shares a common spirit with Gelman and Salop (1983). In their work, the entrant pre-commits to a limited capacity of production to induce the incumbent to accommodate its entry. The findings in these two works - that by taking a less aggressive action, the entrant can share the profit with the incumbent - are qualitatively similar, although in our work there is no capacity limitation on the entrant's side. Three major differences exist between these two works. First, Gelman and Salop (1983) is on entry accommodation as there is no entry without the entrant's capacity restriction. Instead, our work is on entry deterrence as there is always entry without the incumbent's outsourcing. Second, in Gelman and Salop (1983), it is the entrant who commits itself a soft competitor; while in our work it is the incumbent who commits itself a tough competitor after entry. Third, the "judo economy" in Gelman and Salop (1983) can be fragile when there are multiple entrants since the incumbent will find it suboptimal to accommodate several entrants. However, as discussed in Section 5, outsourcing to one entrant can establish a capacity for the incumbent which prevents multiple entrants from producing the final good.

Judd (1985) shows that a multi-product incumbent may withdraw from some markets in response to entry, in order to protect its sale of substitutive goods. In Judd (1985), the entrant makes profit in horizontally related markets by restraining its production scope among substitutive goods. Complementarily, our work illustrates that the entrant can glean profit in vertically related markets by restraining itself to upstream production.

Literature has investigated various factors which have influence on firms' sourcing deci- 
sion. ${ }^{2}$ More related to our work are Baake et al. (1999) and Chen et al. (2009), where they also recognize the endogenous leadership endowed to the buyer in outsourcing. Baake et al. (1999) examine the phenomenon where competing firms supply one another with their final products. The buyer becomes a Stackelberg leader by ordering from a competitor; at the same time, duplicate fixed cost is avoided. Chen et al. (2009) investigate the outsourcing pattern when there exist both pure suppliers and vertically integrated suppliers. When a vertically integrated producer supplies its rival, it becomes a Stackelberg follower in the final-good competition. Foreseeing such a disadvantage, it will charge a high price to drive its rival away. Our work investigates a disparate economic phenomenon. In particular, we show how the sourcing relationship facilitates a tacit collusion which makes entry deterrence desirable for both firms.

A rather sparse literature examines the viability of sourcing in entry deterrence in different contexts. Spiegel (1993) shows that when production exhibits diseconomies of scale, outsourcing to a potential entrant can enhance its future production cost therefore induce it to stay out. In our work, the occurrence of outsourcing does not rely on the strict convexity of cost. Outsourcing may arise even when production exhibits economies of scale, as shown in Section 5. Arya et al. (2008b) find that, outsourcing to a monopoly supplier pre-entry can induce the supplier to favor the entrant less in the post-entry period, hence makes entry unprofitable to the entrant. Instead, in our work the incumbent orders directly from the entrant to deter its entry.

The anticompetitive effect of vertical integration has received lots of attention in literature on vertical foreclosure (see, e.g., Salinger (1988), Ordover et al. (1990), Rey and Tirole (2007)). As a complement, our work illustrates the anticompetitive effect of vertical disintegration. More related literature include Salop (1979), on the incumbent's capability in making entry-deterring binding commitments; Aghion and Bolton (1987), on exclusive contract and entry deterrence; Chen and Ross (2000), on the anticompetitive effect of alliances where incumbents and entrants share production capacity.

\section{The Model and Main Result}

Firm 0 is a monopolist and firm 1 is a potential entrant for a final good $F$. The inverse demand of good $F$ is given by $P(Q)$, where $Q$ is the total quantity of good $F$. For $Q$ not too big such that $P(Q)>0$, it holds that $P^{\prime}(Q)<0, P^{\prime \prime}(Q) \leq 0$.

To produce good $F$ requires a key intermediate good, denoted as good $I$. Both firm 0 and firm 1 can produce good $I$, and the constant marginal $\operatorname{costs}^{3}$ for good $I$ are $c_{0}$ for firm 0 and $c_{1}$ for firm 1. Assume $c_{1}>c_{0}>0 .{ }^{4}$ By investing a fixed fee $K \geq 0$, firm 1 can acquire the same technology as firm 0 in converting good $I$ into good $F$. Assume one unit of good $I$

\footnotetext{
${ }^{2}$ See, e.g., Spiegel (1993), Chen (2001), Shy and Stenbacka (2003), Chen et al. (2004), Shy and Stenbacka (2005), Van Long (2005), Buehler and Haucap (2006), Arya et al. (2008a,b).

${ }^{3}$ The linearity enables us to have a clear view of the central point. It is not critical to our analysis, though, as shown in Section 5.

${ }^{4}$ Assuming $c_{1}>c_{0}$ allows us to focus on the strategic aspect of sourcing. Our model is readily extended to the case when $c_{1} \leq c_{0}$. If $c_{1}<c_{0}$, firm 0 is more eagerly sourcing to firm 1 for efficiency gains. Our key results will not be affected as long as $c_{1}$ is not much smaller than $c_{0}$. If $c_{1}$ is very small, firm 1 will always enter the market of good $F$ to drive firm 0 out and enjoy monopoly profit.
} 
can be converted into one unit of good $F$. W.l.o.g, the constant average cost for producing good $F$ is normalized to zero.

The strategic interaction between firms 0 and 1 is modelled into a three-stage game, denoted as Game $\Gamma$ :

Stage one. Firm 0 and firm 1 negotiate a sourcing contract $\left\{x_{0}^{1}, S\right\}$ on their transaction of good $I$, where $x_{0}^{1} \geq 0$ is the quantity of good $I$ firm 0 orders from firm $1,{ }^{5}$ and $S$ is the total payment firm 0 pays to firm $1 .^{6}$ A binding contract is signed once they reach an agreement.

Stage two. Firm 1 decides whether to enter the market of final good $F$ by investing $K$.

Stage three. Firm 0 and firm 1 decide $\left\{x_{0}, x_{1}\right\}$, the quantity of good $I$ to produce inside, which is unobservable to each other. If firm 1 enters, firms 0 and 1 simultaneously decide $\left\{q_{0}, q_{1}\right\}$, quantities of good $F$. If firm 1 does not enter, firm 0 chooses $q_{0}$ as a monopolist. The quantities are subject to ${ }^{7} q_{0} \leq x_{0}+x_{0}^{1} ; q_{1} \leq x_{1}-x_{0}^{1}$.

Game $\Gamma$ is solved by backward induction for subgame perfect Nash equilibrium (SPNE). Since $c_{1}>0$, once firm 1 enters for good $F$, in any equilibrium $x_{1}=x_{0}^{1}+q_{1}$. Let $\delta=1$ if firm 1 enters for good $F$ and $\delta=0$ if it stays out. At the terminal nodes of the game tree, profit for each firm is

$$
\begin{gathered}
\begin{cases}\Pi_{0}^{e}\left(x_{0}^{1}, S, x_{0}, q_{0}, q_{1}\right)=P\left(q_{0}+q_{1}\right) q_{0}-S-c_{0} x_{0} & \text { if } \delta=1 \\
\Pi_{0}^{n}\left(x_{0}^{1}, S, x_{0}, q_{0}, q_{1}\right)=P\left(q_{0}\right) q_{0}-S-c_{0} x_{0} & \text { if } \delta=0\end{cases} \\
\begin{cases}\Pi_{1}^{e}\left(x_{0}^{1}, S, x_{0}, q_{0}, q_{1}\right)=P\left(q_{0}+q_{1}\right) q_{1}+S-c_{1}\left(x_{0}^{1}+q_{1}\right)-K & \text { if } \delta=1 \\
\Pi_{1}^{n}\left(x_{0}^{1}, S, x_{0}, q_{0}, q_{1}\right)=S-c_{1} x_{0}^{1} & \text { if } \delta=0\end{cases}
\end{gathered}
$$

Our main result to Game $\Gamma$ asserts that, under certain circumstances, in SPNE firm 0 sources to firm 1 certain quantity of good $I$ for the sole purpose of deterring firm 1 's entry.

The Main Result: As long as $c_{1} \in\left(c_{0}, \bar{c}_{1}\right)$ where $\bar{c}_{1}>c_{0}$, there exists a non-empty range of $K$, where in SPNE firm 0 sources $\tau(K)>0$ of good I to firm 1 to deter firm 1 's entry. If there is no such outsourcing, firm 1 always enters for good $F$.

Two effects of firm 0's sourcing to firm 1 work together to serve entry deterrence. First, there is a "capacity-building" effect. The outsourced quantity functions as a built-up capacity of firm 0 before firm 1's entry. As long as firm 0 produces good $F$ within such a capacity, its marginal cost when competing with firm 1 decreases from $c_{0}$ to 0 . Thus by outsourcing, firm 0 is able to commit to a more aggressive response towards entry, which raises entry barrier to firm 1. Second, there is a collusive effect. The profit in the market of good $F$ without firm 1's entry can exceed the joint duopoly profit net of the entry cost, inducing both firms to engage in outsourcing in order to benefit from entry deterrence.

\footnotetext{
${ }^{5}$ Our key results are well preserved when we allow for firm 1 to order good $I$ from firm 0 . See Section 5 for a discussion.

${ }^{6}$ To focus on our central point, we consider a lump sum payment for the shipment of good $I$, and do not explicitly assume how firms 0 and 1 split the surplus generated by outsourcing. Our major finding persists under alternative pricing schemes, including linear pricing and two-part tariff. Section 5 gives a discussion.

${ }^{7}$ The inequality here is equivalent to assuming free disposal of good $I$ for both firms. I.e., no cost will occur if either firm leaves some of its acquired good $I$ unused, without converting them into good $F$.
} 


\section{Model Analysis}

In this section, we do backward induction to solve Game $\Gamma$. The SPNE of Game $\Gamma$ will be fully characterized on the last step. We start from finding the Nash equilibrium (NE) quantities and profits in stage three for given sourcing decisions and entry decisions.

\subsection{Stage Three}

There are two cases in stage three according to firm 1's entry decision in stage two: either firm 1 has entered or it has stayed out.

Case I. Firm 1 enters for good $F$. In this case, firms 0 and 1 move simultaneously by choosing quantities for good $F$. Firm 1 maximizes $\Pi_{1}^{e}\left(x_{0}^{1}, S, x_{0}, q_{0}, q_{1}\right)$. Since producing $x_{0}$ incurs marginal cost $c_{0}>0$ to firm 0 , in equilibrium $x_{0}=q_{0}-x_{0}^{1}$ if $q_{0}>x_{0}^{1}$. Firm 0's problem is

$$
\max _{q_{0}} \Pi_{0}^{e}\left(x_{0}^{1}, S, x_{0}, q_{0}, q_{1}\right)= \begin{cases}P\left(q_{0}+q_{1}\right) q_{0}-S-c_{0}\left(q_{0}-x_{0}^{1}\right) & \text { if } q_{0}>x_{0}^{1} \\ P\left(q_{0}+q_{1}\right) q_{0}-S & \text { otherwise. }\end{cases}
$$

If $q_{0}>x_{0}^{1}$, firm 0's marginal cost is $c_{0}$; if $q_{0}<x_{0}^{1}$, firm 0's marginal cost is 0 .

Figure 1 displays the best response curves in stage three. Firm 1's best response curve is $R R^{\prime}$. firm 0 's best response curve is kinked at $q_{0}=x_{0}^{1}$, as shown by the heavy curve. If firm 0's marginal cost is $c_{0}$, its best response curve is $M M^{\prime}$, intersecting $R R^{\prime}$ at point $W$. If firm 0 's marginal cost is 0 , its best response curve is $O O^{\prime}$, intersecting $R R^{\prime}$ at point $V$. Let quantities at point $W$ and $V$ be $\left(q_{0}^{W}, q_{1}^{W}\right)$ and $\left(q_{0}^{V}, q_{1}^{V}\right)$, respectively. Notice that since best response curves are downward-sloping, $q_{0}^{V}>q_{0}^{W}>0 .{ }^{8}$

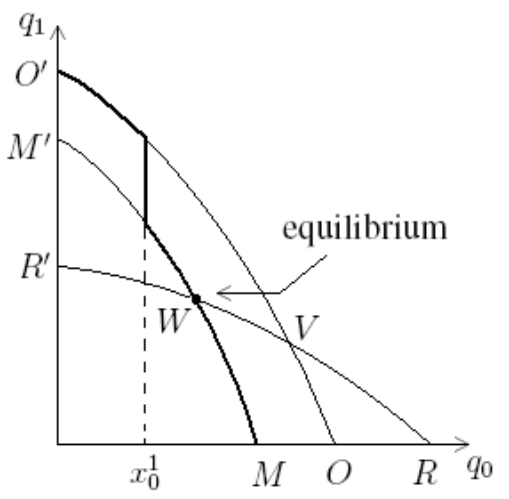

Subcase 1

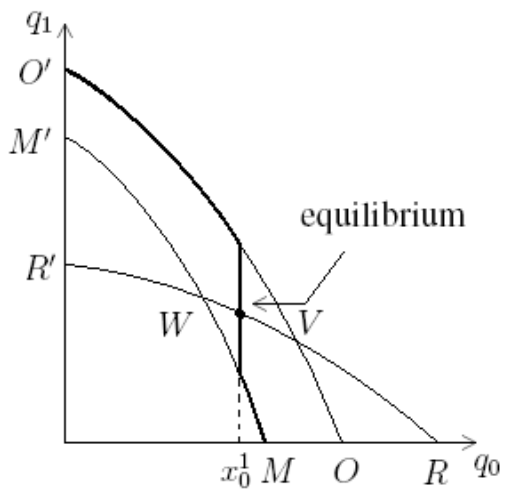

Subcase 2

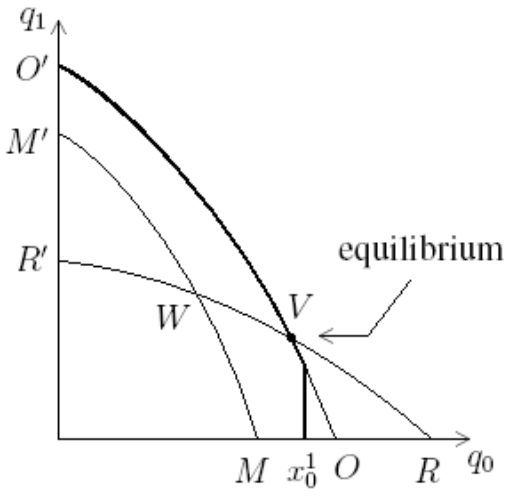

Subcase 3

Figure 1: Post-entry Best Response Curves

If $x_{0}^{1}>0$, the competition in stage three is a Cournot game where firm 0 has built a capacity of $x_{0}^{1}$. There are three subcases according to the value of $x_{0}^{1}$ :

Subcase 1. $x_{0}^{1}<q_{0}^{W}$. Best response curves intersect at point $W$, which is the standard Cournot outcome when firm 0 faces marginal cost $c_{0}$. We define the autarky duopoly profits as

$$
\left(\pi_{0}^{W}, \pi_{1}^{W}\right)=\left(P\left(q_{0}^{W}+q_{1}^{W}\right) q_{0}^{W}-c_{0} q_{0}^{W}, P\left(q_{0}^{W}+q_{1}^{W}\right) q_{1}^{W}-c_{1} q_{1}^{W}\right) .
$$

\footnotetext{
${ }^{8}$ We assume $q_{1}^{W}>0$ throughout our analysis. Otherwise, firm 1 shall never enter for good $F$.
} 
Subcase 2. $x_{0}^{1} \in\left[q_{0}^{W}, q_{0}^{V}\right]$. Best response curves intersect at $q_{0}=x_{0}^{1}$. Firm 0 produces exactly the outsourced quantity $x_{0}^{1}$ for good $F$. Understanding this, firm 1 will produce its best response to $x_{0}^{1}$. Therefore, sourcing $x_{0}^{1} \in\left[q_{0}^{W}, q_{0}^{V}\right]$ to firm 1 effectively establishes firm 0 as a Stackelberg leader and forces firm 1 into a Stackelberg follower in the market of good $F$. The largest quantity firm 0 is able to commit to through outsourcing is $q_{0}^{V}$.

For any given $q_{i}$ of firm $i$, denote firm $j$ 's best response as $q_{j}^{b}\left(q_{i}\right), i, j=0,1, i \neq j$, solved from the first order condition $P^{\prime}\left(q_{i}+q_{j}\right) q_{j}+P\left(q_{i}+q_{j}\right)-c_{j}=0$. We have

$$
\frac{d\left(q_{i}+q_{j}^{b}\left(q_{i}\right)\right)}{d q_{i}}=1-\frac{P^{\prime \prime} q_{j}^{b}\left(q_{i}\right)+P^{\prime}}{P^{\prime \prime} q_{j}^{b}\left(q_{i}\right)+2 P^{\prime}}>0 .
$$

In Subcase 2, firm 0 faces zero marginal cost since it produces zero amount in-house for good I. The Stackelberg leader and follower's profits for firms 0 and 1 are

$$
\left(\pi_{0}^{l}\left(q_{0}\right), \pi_{1}^{f}\left(q_{0}\right)\right)=\left(P\left(q_{0}+q_{1}^{b}\left(q_{0}\right)\right) q_{0}, P\left(q_{0}+q_{1}^{b}\left(q_{0}\right)\right) q_{1}^{b}\left(q_{0}\right)-c_{1} q_{1}^{b}\left(q_{0}\right)\right) .
$$

The smallest $q_{0}$ at which $q_{1}^{b}\left(q_{0}\right)=0$ is given by point $R$ and denoted as $q_{0}^{R}$. It is useful to note that, for $q_{0} \in\left[0, q_{0}^{R}\right), \pi_{1}^{f}\left(q_{0}\right)$ is strictly decreasing in $q_{0}$ since by the envelop theorem,

$$
\frac{d \pi_{1}^{f}\left(q_{0}\right)}{d q_{0}}=P^{\prime}\left(q_{0}+q_{1}^{b}\left(q_{0}\right)\right) q_{1}^{b}\left(q_{0}\right)<0 .
$$

Subcase 3. $x_{0}^{1}>q_{0}^{V}$. Best response curves intersect at point $V$, which is the Cournot outcome when firm 0 faces zero marginal cost. There are $x_{0}^{1}-q_{0}^{V}$ amount of good $I$ left unused, without being converted into good $F$. Define the NE profits of the Cournot game where firm 0 has zero marginal cost as

$$
\left(\pi_{0}^{V}, \pi_{1}^{V}\right)=\left(P\left(q_{0}^{V}+q_{1}^{V}\right) q_{0}^{V}, P\left(q_{0}^{V}+q_{1}^{V}\right) q_{1}^{V}-c_{1} q_{1}^{V}\right) .
$$

Case II. Firm 1 stays out for good $F$. As a monopolist of good $F$, firm 0's problem is

$$
\max _{q_{0}} \Pi_{0}^{n}\left(x_{0}^{1}, S, x_{0}, q_{0}, q_{1}\right)= \begin{cases}P\left(q_{0}\right) q_{0}-S-c_{0}\left(q_{0}-x_{0}^{1}\right) & \text { if } q_{0}>x_{0}^{1} \\ P\left(q_{0}\right) q_{0}-S & \text { otherwise. }\end{cases}
$$

Same as in Case I, if $q_{0}>x_{0}^{1}$, firm 0's marginal cost is $c_{0}$; if $q_{0}<x_{0}^{1}$, firm 0's marginal cost is zero. Define firm 0 monopoly quantity at zero marginal cost as $q_{0}^{O} \equiv \arg \max _{q_{0}} P\left(q_{0}\right) q_{0}$. Define firm $i$ 's monopoly quantity at marginal cost $c_{i}$ as $q_{i}^{M} \equiv \arg \max _{q_{i}} P\left(q_{i}\right) q_{i}-c_{i} q_{i}$, and its corresponding monopoly profit as $\pi_{i}^{M}, i=0,1$. The following lemma derives the NE quantities and profits in stage three.

Lemma 1 There exists a unique NE in stage three.

I When firm 1 enters for good $F$,

$a$ if $x_{0}^{1}<q_{0}^{W}$, then $x_{0}=q_{0}^{W}-x_{0}^{1},\left(q_{0}, q_{1}\right)=\left(q_{0}^{W}, q_{1}^{W}\right)$. Profits are $\left(\pi_{0}^{e}\left(x_{0}^{1}\right), \pi_{1}^{e}\left(x_{0}^{1}\right)\right)=$ $\left(\pi_{0}^{W}+c_{0} x_{0}^{1}, \pi_{1}^{W}\right)$;

$b$ if $x_{0}^{1} \in\left[q_{0}^{W}, q_{0}^{V}\right]$, then firm 0 becomes a Stackelberg leader and firm 1 becomes a Stackelberg follower. We have $x_{0}=0,\left(q_{0}, q_{1}\right)=\left(x_{0}^{1}, q_{1}^{b}\left(x_{0}^{1}\right)\right)$. Profits are $\left(\pi_{0}^{e}\left(x_{0}^{1}\right), \pi_{1}^{e}\left(x_{0}^{1}\right)\right)=$ $\left(\pi_{0}^{l}\left(x_{0}^{1}\right), \pi_{1}^{f}\left(x_{0}^{1}\right)\right)$; 
$c$ if $x_{0}^{1}>q_{0}^{V}$, then $x_{0}=0,\left(q_{0}, q_{1}\right)=\left(q_{0}^{V}, q_{1}^{V}\right)$. Profits are $\left(\pi_{0}^{e}\left(x_{0}^{1}\right), \pi_{1}^{e}\left(x_{0}^{1}\right)\right)=\left(\pi_{0}^{V}, \pi_{1}^{V}\right)$.

II When firm 1 stays out for good F,

a if $x_{0}^{1}<q_{0}^{M}$, then $x_{0}=q_{0}^{M}-x_{0}^{1}, q_{0}=q_{0}^{M}$. Profit of firm 0 is $\pi_{0}^{n}\left(x_{0}^{1}\right)=\pi_{0}^{M}+c_{0} x_{0}^{1}$;

$b$ if $x_{0}^{1} \in\left[q_{0}^{M}, q_{0}^{O}\right]$, then $x_{0}=0, q_{0}=x_{0}^{1}$. Profit of firm 0 is $\pi_{0}^{n}\left(x_{0}^{1}\right)=P\left(x_{0}^{1}\right) x_{0}^{1}$;

$c$ if $x_{0}^{1}>q_{0}^{O}$, then $x_{0}=0, q_{0}=q_{0}^{O}$. Profit of firm 0 is $\pi_{0}^{n}\left(x_{0}^{1}\right)=P\left(q_{0}^{O}\right) q_{0}^{O}$.

Based on Lemma 1 , at given $\left\{x_{0}^{1}, S\right\}$, total equilibrium profit of each firm when firm 1 enters for $\operatorname{good} F$ is

$$
\left(\Pi_{0}^{e}\left(S, x_{0}^{1}\right), \Pi_{1}^{e}\left(S, x_{0}^{1}\right)\right)=\left(\pi_{0}^{e}\left(x_{0}^{1}\right)-S, \pi_{1}^{e}\left(x_{0}^{1}\right)-K+S-c_{1} x_{0}^{1}\right) .
$$

Instead, when firm 1 stays out, total equilibrium profit of each firm is

$$
\left(\Pi_{0}^{n}\left(S, x_{0}^{1}\right), \Pi_{1}^{n}\left(S, x_{0}^{1}\right)\right)=\left(\pi_{0}^{n}\left(x_{0}^{1}\right)-S, S-c_{1} x_{0}^{1}\right) .
$$

We then move back to stage two to find the entry rule of firm 1.

\subsection{Stage Two}

W.l.o.g., we assume that if firm 1 is indifferent between entering or not, it stays out. Thus firm 1 enters for good $F$ if and only if its post-entry profit exceeds the entry cost, i.e., $\pi_{1}^{e}\left(x_{0}^{1}\right)>K$. By Lemma 1 and the continuity of $\pi_{1}^{f}\left(x_{0}^{1}\right)$, we have $\pi_{1}^{e}\left(x_{0}^{1}\right) \in\left[\pi_{1}^{V}, \pi_{1}^{W}\right]$. If $K \geq \pi_{1}^{W}$, firm 1 never enters. By Bain's terminology (see Bain (1956)), entry is blockaded. Instead, if $K<\pi_{1}^{V}$, firm 1 always enters irrespective of $x_{0}^{1}$, and entry is unavoidable. For $K \in\left[\pi_{1}^{V}, \pi_{1}^{W}\right)$, there exists a threshold value of $x_{0}^{1}$, below which firm 1 is profitable entering for $\operatorname{good} F$.

Define function $\tau(K):\left[0, \pi_{1}^{M}\right] \rightarrow\left[0, q_{0}^{R}\right]$ as

$$
\tau \equiv \tau(K) \equiv\left\{q_{0} \mid \pi_{1}^{f}\left(q_{0}\right)=K\right\}
$$

Notice that $\tau$ is strictly decreasing in $K$ and $c_{1}$ since for $\tau<q_{0}^{R}$,

$$
\frac{d \tau}{d c_{1}}=\frac{1}{P^{\prime}\left(\tau+q_{1}^{b}(\tau)\right)}<0, \quad \frac{d \tau}{d K}=\frac{1}{P^{\prime}\left(\tau+q_{1}^{b}(\tau)\right) q_{1}^{b}(\tau)}<0 .
$$

Throughout our following analysis, we focus on $K \in\left[\pi_{1}^{V}, \pi_{1}^{W}\right)$, the range of interests. The following lemma summarizes firm 1's entry rule. (All proofs are in the Appendix.)

Lemma 2 In SPNE, firm 1 enters if and only if $x_{0}^{1}<\tau$, with $\tau \in\left(q_{0}^{W}, \min \left\{q_{0}^{V}, q_{0}^{R}\right\}\right]$.

When firm 0 establishes a capacity of at least $\tau$ through sourcing to firm 1 , firm 1 's Stackelberg follower's profit of good $F$ is no larger than its entry cost $K$. As a result, firm 1 will not enter to produce good $F$. The threshold capacity $\tau$ decreases in $K$ and $c_{1}$. The reason is, a smaller value of $K$ or $c_{1}$ gives firm 1 a stronger incentive to enter and compete firm 0 . Therefore, firm 0 needs to take a more aggressive stance towards entry in order to keep firm 1 out, which is reflected by an increase in the threshold capacity $\tau$. 


\subsection{Stage One}

We move back to stage one, where firms 0 and 1 discuss their sourcing transaction for good I. W.l.o.g, if both firms are indifferent between reaching an outsourcing agreement $\left(x_{0}^{1}>0\right)$ or not $\left(x_{0}^{1}=0\right)$, we assume that no outsourcing will take place.

When firm 0 anticipates firm 1's entry, it has incentive to source to firm 1 quantity $x_{0}^{1}>q_{0}^{W}$ in order to exploit its Stackelberg leader's advantage in their future competition. However, the following lemma shows that, no outsourcing can occur if firm 1 enters.

Lemma 3 In any SPNE, if firm 1 enters for good $F$, it must be $x_{0}^{1}=0$, with profits for firm 0 and firm 1 being $\left(\Pi_{0}^{e}, \Pi_{1}^{e}\right)=\left(\pi_{0}^{W}, \pi_{1}^{W}-K\right)$ respectively.

If outsourcing is followed by firm 1's entry, although firm 0 can be better off ordering $x_{0}^{1}>q_{0}^{W}$ from firm 1 to force the latter into a Stackelberg follower for good $F$, industry profit is reduced because the Stackelberg quantity is larger than the Cournot quantity. Therefore, at least one firm will refuse to contract in stage one in order to secure its autarky duopoly profit. As a result, no outsourcing can occur, and each firm gets the autarky duopoly profit.

Therefore, sourcing from firm 0 to firm 1 only occurs for entry-deterring purpose. Denote the industry profit without entry as $\xi^{n}\left(x_{0}^{1}\right) \equiv \Pi_{0}^{n}\left(S, x_{0}^{1}\right)+\Pi_{1}^{n}\left(S, x_{0}^{1}\right)$. Since outsourcing leads to an efficiency loss and firms are maximizing industry profit in outsourcing, the following lemma is intuitive.

Lemma 4 In any SPNE, if firm 1 stays out for good $F$, it must be $x_{0}^{1}=\tau$. Moreover, outsourcing arises in equilibrium if and only if

$$
\xi^{n}(\tau)>\pi_{0}^{W}+\pi_{1}^{W}-K
$$

The right-hand-side of Condition (6) is the joint autarky duopoly profit net of the entry cost. Condition (6) says that outsourcing will arise in equilibrium whenever it generates a joint surplus with respect to the autarky case. Moreover, in outsourcing it must be $x_{0}^{1}=$ $\tau \leq \min \left\{q_{0}^{V}, q_{0}^{R}\right\} \leq q_{0}^{O}$. By Lemma 1, with firm 1's entry deterred, firm 0 produces $q_{0}^{d}=$ $\max \left\{q_{0}^{M}, \tau\right\}$ for good $F$, and the corresponding industry profit is $\xi^{n}(\tau)$, given by (8) in the Appendix. A tacit collusion exists with the entry-deterring outsourcing. The following lemma gives the range of parameters within which Condition (6) can hold.

Lemma 5 There exist $\bar{K}>0$ and $\bar{c}_{1}>c_{0}$, defined by

$$
\begin{gathered}
\bar{K} \equiv\left\{K \mid \xi^{n}(\tau)=\pi_{0}^{W}+\pi_{1}^{W}-K\right\}, \\
\bar{c}_{1} \equiv\left\{c_{1} \mid\left(c_{1}-c_{0}\right) q_{0}^{W}=\pi_{0}^{M}-\pi_{0}^{W}\right\} .
\end{gathered}
$$

Condition (6) holds if and only if $K>\bar{K}$. Moreover, $\bar{K}<\pi_{1}^{W}$ when $c_{1}<\bar{c}_{1}$.

The intuition of Lemma 5 is spelled out below. In order to deter firm 1's entry, the smaller the value of $K$, the larger the quantity firm 0 needs to commit to through sourcing to firm 1. However, a large quantity can reduce the industry profit to be no larger than the joint autarky duopoly profit net of the entry cost, leading to no outsourcing. The lower bound of $K$ for outsourcing to occur is given by $\bar{K}$, which solves Condition (6) at equality. At $K=\bar{K}$, industry profits are the same with and without entry deterrence. 
If we fix the value of $K$, then outsourcing occurs if $c_{1}$ is not too big. The largest value of $K$ leaves the largest scope of $c_{1}$ where outsourcing can occur in equilibrium. Therefore, the upper bound of $c_{1}$ for outsourcing to arise is solved from setting Condition (6) at equality while inserting $K=\pi_{1}^{W}$. In this case, firm 1 gets zero profit no matter it enters or not. To deter entry, firm 0 needs to outsource $\tau=q_{0}^{W}$, leading to efficiency loss $\left(c_{1}-c_{0}\right) q_{0}^{W}$. Meanwhile, entry deterrence generates a gross gain given by the difference between monopoly profit $\pi_{0}^{M}$ and firm 0's autarky duopoly profit $\pi_{0}^{W}$. The upper bound of $c_{1}$ is given by $\bar{c}_{1}$ in Lemma 5, which balances the efficiency loss and the gross gain of entry deterrence.

\subsection{SPNE of Game $\Gamma$}

Before we fully characterize the SPNE of Game $\Gamma$, it is useful to define

$$
\Psi \equiv \begin{cases}{\left[\pi_{1}^{V}, \pi_{1}^{W}\right)} & \text { if } \quad \bar{K}<\pi_{1}^{V} \\ \left(\bar{K}, \pi_{1}^{W}\right) & \text { if } \quad \bar{K} \geq \pi_{1}^{V}\end{cases}
$$

Note that by Lemma $5, \Psi \neq \varnothing$ when $c_{1}<\bar{c}_{1}$. Also define $K^{M} \equiv \pi_{1}^{f}\left(q_{0}^{M}\right) \in\left(0, \pi_{1}^{W}\right) .{ }^{9}$ The following theorem then characterize the SPNE of Game $\Gamma$.

Theorem 1 For $K \in\left[\pi_{1}^{V}, \pi_{1}^{W}\right)$, the SPNE of Game $\Gamma$ is given as below.

I If $K \in \Psi$, firm 1's entry is deterred by firm 0. In SPNE, $x_{0}^{1}=\tau$ and $S \in\left[c_{1} x_{0}^{1}+\pi_{1}^{W}-\right.$ $\left.K, \xi^{n}(\tau)-\left(\pi_{0}^{W}+\pi_{1}^{W}-K\right)\right]$. Moreover, if $K \geq K^{M}$, firm 0 produces $x_{0}=q_{0}^{M}-\tau, q_{0}=q_{0}^{M}$; if $K<K^{M}$, firm 0 produces $x_{0}=0, q_{0}=\tau$.

II If $K \notin \Psi$, firm 1's entry is accommodated by firm 0. In SPNE, $x_{0}^{1}=0, q_{0}=x_{0}=$ $q_{0}^{W}, q_{1}=x_{1}=q_{1}^{W}$.

Our major result for $c_{1} \in\left[c_{0}, \bar{c}_{1}\right)$ is also illustrated in Figure 2, where $K$ varies on the axis. To have the whole picture, we allow for $K<\pi_{1}^{V}$ and $K \geq \pi_{1}^{W}$.

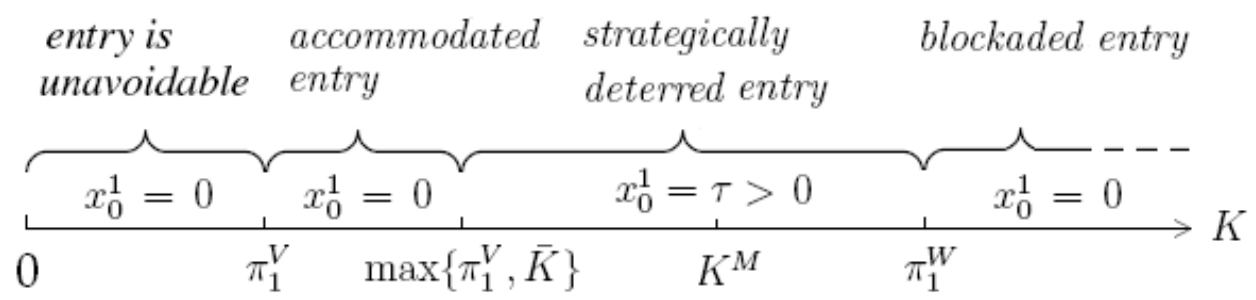

Figure 2: SPNE

Two effects of firm 0's outsourcing work simultaneously to serve entry deterrence. On the one side, $x_{0}^{1}=\tau$ builds up a sizable capacity for firm 0 prior to firm 1's entry, which effectively raises entry barrier to firm 1 . On the other side, a tacit collusion exists. Through sharing the joint surplus generated by a more concentrated final-good market, both firms can be better off.

\footnotetext{
${ }^{9}$ See proof of Lemma 4 in the Appendix.
} 
We then check the welfare effect of outsourcing. Consider $c_{1} \in\left[c_{0}, \bar{c}_{1}\right)$ and $K \in \Psi$. We define social welfare as the summation of firm surplus and consumer surplus. It is clear that firms are better off under outsourcing, yet consumers may get worse off when outsourcing reduces the quantity of good $F$. Let us take no outsourcing as the status quo, then $Q^{W} \equiv$ $q_{0}^{W}+q_{1}^{W}$ is the status quo quantity. Status quo social welfare is $S W^{S}=\int_{0}^{Q^{W}} P d q-c_{0} q_{0}^{W}-$ $c_{1} q_{1}^{W}-K$; and social welfare under outsourcing is $S W^{O}=\int_{0}^{q_{0}^{d}} P d q-c_{1} \tau-c_{0}\left(q_{0}^{d}-\tau\right)$. Outsourcing generates a distortion in social welfare, given as

$$
\begin{aligned}
D(K) & =S W^{O}-S W^{S} \\
& = \begin{cases}K+\int_{Q^{W}}^{q^{M}} P d q+\left[c_{0}\left(q_{0}^{W}-q_{0}^{M}+\tau\right)+c_{1}\left(q_{1}^{W}-\tau\right)\right] & \text { if } \quad K \geq K^{M} \\
K+\int_{Q^{W}}^{\gamma} P d q+\left[c_{0} q_{0}^{W}+c_{1}\left(q_{1}^{W}-\tau\right)\right] & \text { if } K<K^{M}\end{cases}
\end{aligned}
$$

$D(K)$ includes three parts: the saving of entry cost $K$; the distortion in welfare due to the quantity change from $Q^{W}$ to $q_{0}^{d}=\max \left\{q_{0}^{M}, \tau\right\}$; and the distortion in welfare due to the change in cost structure. While the first part is positive, the second and last parts can be either positive or negative. The social welfare effect of outsourcing is in general ambiguous. There are two cases where outsourcing increases social welfare. In the first case, the entry cost is big and outsourcing enhances social welfare by preventing excessive entry. However, consumers are worse off since the quantity of good $F$ is firm 0's monopoly quantity $q_{0}^{M}$, which is less than the duopoly quantity $Q^{W}$. In the second case, entry cost is relatively small. To deter entry, firm 0 needs to outsource good $I$ at a quantity relatively large, which is fully converted into good $F$ and leads to a moderate consumers' loss. When the moderate consumers' loss together with efficiency loss are dominated by the saving of the entry cost, social welfare increases. Furthermore, consumers can even be benefited when the entry cost is sufficiently low so that deterring entry leads to a quantity larger than $Q^{W}$. In particular, as long as $\pi_{1}^{f}\left(Q^{W}\right) \in \Psi$, outsourcing increases consumers' welfare for $K<\pi_{1}^{f}\left(Q^{W}\right)$.

Proposition 1 Consider $c_{1} \in\left[c_{0}, \bar{c}_{1}\right)$ and $K \in \Psi$. If $c_{0}$ is not too close to zero, we have $\pi_{1}^{f}\left(Q^{W}\right) \in \Psi$. Outsourcing increases consumers' welfare for $K<\pi_{1}^{f}\left(Q^{W}\right)$.

An Example. Suppose $P=\max \{0, a-Q\}$, with $Q=q_{0}+q_{1}$. Assume $\left(a+c_{0}\right) / 2>c_{1}>$ $c_{0}>0$. The first inequality is to prevent firm 0 from automatically becoming a monopolist. We can easily calculate the following values:

$$
\begin{gathered}
\left(q_{0}^{W}, q_{1}^{W}\right)=\left(\frac{a+c_{1}-2 c_{0}}{3}, \frac{a+c_{0}-2 c_{1}}{3}\right) ; q_{0}^{M}=\frac{a-c_{0}}{2} \\
\left(q_{0}^{V}, q_{1}^{V}\right)=\left(\frac{a+c_{1}}{3}, \frac{a-2 c_{1}}{3}\right) ; q_{0}^{R}=a-c_{1} \\
\left(\pi_{0}^{W}, \pi_{1}^{W}\right)=\left(\frac{\left(a+c_{1}-2 c_{0}\right)^{2}}{9}, \frac{\left(a+c_{0}-2 c_{1}\right)^{2}}{9}\right) ; \pi_{0}^{M}=\frac{\left(a-c_{0}\right)^{2}}{4} ; \pi_{1}^{V}=\frac{\left(a-2 c_{1}\right)^{2}}{9}
\end{gathered}
$$

Consider $K \in\left[\pi_{1}^{V}, \pi_{1}^{W}\right)$. Suppose $a \geq 2 c_{1}$, so that we have $q_{0}^{V} \leq q_{0}^{R}$. When $x_{0}^{1} \in\left[q_{0}^{W}, q_{0}^{V}\right]$, firm 1 is forced into a Stackelberg follower upon its entry. Its follower's quantity for good $F$ is solved from $\max _{q_{1}}\left\{\left(a-x_{0}^{1}-q_{1}\right) q_{1}-c_{1} q_{1}\right\}$ as $q_{1}^{b}\left(x_{0}^{1}\right)=\frac{a-c_{1}-x_{0}^{1}}{2}$. Its Stackelberg follower's 
profit is $\pi_{1}^{f}\left(x_{0}^{1}\right)=\frac{\left(a-c_{1}-x_{0}^{1}\right)^{2}}{4}$, strictly decreasing in $x_{0}^{1}$. The minimum amount of $x_{0}^{1}$ for firm 1 to stay out is given by $\tau$, which is solved from $\pi_{1}^{f}\left(x_{0}^{1}\right)=K$ as

$$
\tau=a-c_{1}-2 \sqrt{K} \text {. }
$$

Moreover, $K^{M}=\pi_{1}^{f}\left(q_{0}^{M}\right)=\frac{\left(a+c_{0}-2 c_{1}\right)^{2}}{16}$. It is verified that $\tau>q_{0}^{M}$ when $K<K^{M}$.

By Lemma 5, the upper bound of $c_{1}$ at which entry can be deterred is solved from $\left(c_{1}-c_{0}\right) q_{0}^{W}=\pi_{0}^{M}-\pi_{0}^{W}$ as $\bar{c}_{1}=\frac{3 \sqrt{5}-5}{40}\left(5 a+5 c_{0}+6 \sqrt{5} c_{0}\right)$. Note that $\bar{c}_{1} \in\left(c_{0},\left(a+c_{0}\right) / 2\right)$. For $c_{1} \in\left[c_{0}, \bar{c}_{1}\right)$, there exists a non-empty range of $K$, under which firm 0 orders good $I$ from firm 1 to deter its entry. The lower bound $\bar{K}$ is solved from $\xi^{n}(\tau)=\pi_{0}^{W}+\pi_{1}^{W}-K$, with

$$
\xi^{n}(\tau)=\left\{\begin{array}{lll}
(a-\tau) \tau-c_{1} \tau & \text { if } K \in\left[\pi_{1}^{V}, K^{M}\right] \\
\left(a-q_{0}^{M}\right) q_{0}^{M}-c_{1} \tau-c_{0}\left(q_{0}^{M}-\tau\right) & \text { if } K \in\left(K^{M}, \pi_{1}^{W}\right) .
\end{array}\right.
$$

Figure 3 illustrates the SPNE entry strategy of the example, where parameters are set as $a=10, c_{0}=3.5$. The shaded area gives the range of parameters where firm 0 outsources $x_{0}^{1}=\tau$ to deter firm 1's entry. In the hatched area, firm 1's entry is deterred and $K<$ $\pi_{1}^{f}\left(Q^{W}\right)=\frac{\left(a+c_{0}-2 c_{1}\right)^{2}}{36}$ is satisfied, implying that equilibrium quantity of good $F$ exceeds $Q^{W}$. In this area, outsourcing increases consumers' welfare.

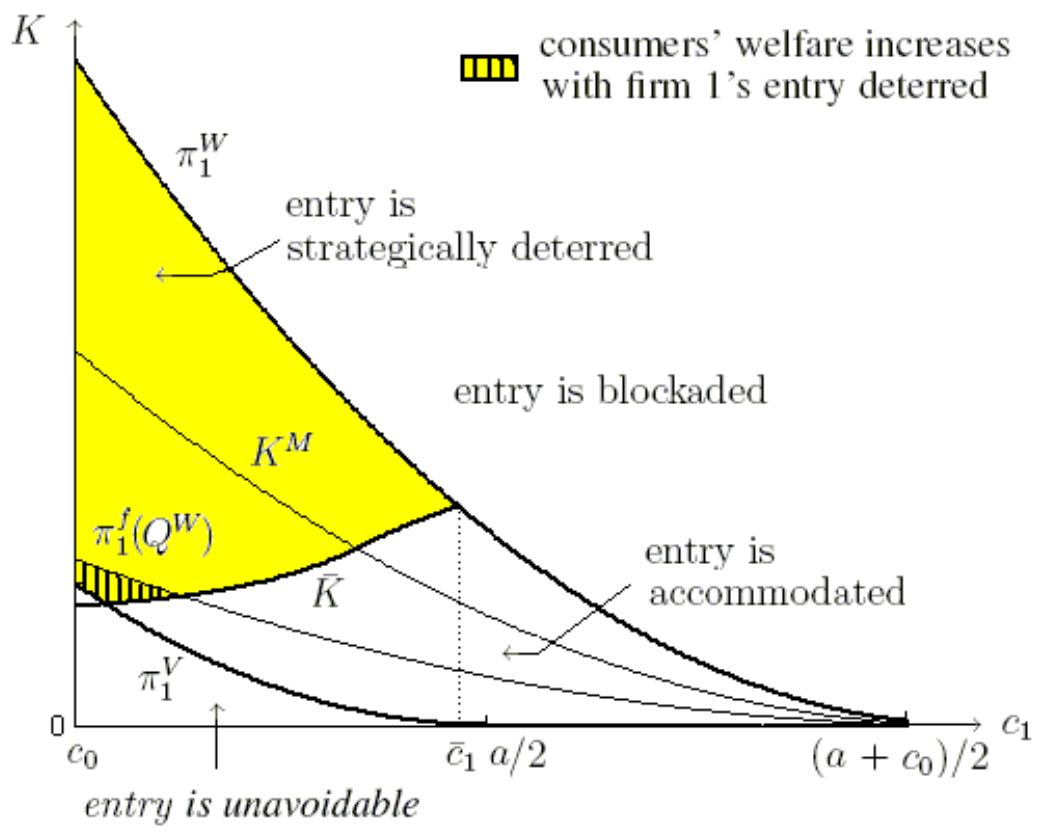

Figure 3: A Linear Example

\section{Discussions and Model Variations}

\subsection{Alternatives of Quantity Revelation: Public Announcement or Capacity Building}

A critical assumption in our model is that firm 0's in-house production is unobservable to firm 1. Since firm 0 has strong interests in revealing its quantity to firm 1 and outsourcing 
is a costly method of quantity revelation, a natural question to ask is if there exists better alternatives for firm 0 to credibly reveal its quantity.

First, suppose firm 0 publicly announces a big quantity of good $F$ before firm 1's entry decision. In the lack of an outside authority which can force firm 0 to fulfill its announcement, such announcement is just "cheap talk" and is incredible to firm 1 . To see this, let firm 0 announces $q_{0} \geq \tau$ before firm 1's entry. If firm 1 enters, the logic of SPNE then predicts that firm 0 will accommodate entry by producing $q_{0}^{W}<\tau$, rather than fulfilling its announcement. In fact, any announced quantity larger than $q_{0}^{W}$ is incredible hence will be ignored by firm 1 when making its entry decision. Therefore, a publicly announced quantity does not acquire the same commitment power for firm 0 as outsourcing does.

Second, Dixit (1980) shows that, an incumbent can build up capacity to credibly reveal its future production scale therefore restrict entry. However, previous literature points out that, if capacity is only observed with some noise, or if there is positive observation cost to the entrant, capacity built before entry may totally lose its value in entry deterrence. ${ }^{10}$ This might explain to some extent the lack of empirical evidence on capacity building as constituting an entry barrier (see, e.g., Hilke (1984), Lieberman(1987), Goolsbee and Syverson(2008)). Instead, with outsourcing to deter entry, the entrant shall naturally get informed the exact quantity it is obligated to supply to the incumbent. Observability problems are unlikely to arise, especially when we take into consideration that entry deterrence through outsourcing is in both firms' interests.

Moreover, even when we assume away all these observability problems for capacitybuilding, there are scenarios where the incumbent chooses outsourcing rather than capacitybuilding to serve its purpose of entry deterrence. To see this, consider an extended game where we impose one more stage before Game $\Gamma$ is played out, in which firm 0 chooses between outsourcing and building its own capacity for good $I$. A pre-built capacity can be expanded if firm 0 wants to produce beyond the established capacity. For comparison, we keep firm 0's total average cost for good $I$ be $c_{0}$ under capacity-building: the constant average cost of building capacity is $(1-\alpha) c_{0}$; and the constant average cost of producing good $I$ within the constructed capacity is $\alpha c_{0}$, with $\alpha \in[0,1]$.

Figure 4 depicts the SPNE entry-deterring strategy adopted by firm 0 to the extended game. Given entry cost $K$, whenever $\alpha$ is not too small, firm 0 chooses outsourcing rather than capacity-building to deter firm 1's entry. The reason is, with capacity-building, when firm 0 produces within the established capacity, it still faces $\alpha c_{0}$ as its marginal cost in the market of good $F$. Instead, with outsourcing, its marginal cost is reduced to zero. Whenever $\alpha>0$, outsourcing enables firm 0 to commit to a harsher post-entry competition upon firm 1's entry, therefore is more efficient in entry-deterrence than capacity-building. For relatively large $\alpha$, the threshold capacity $\tau$ can lie beyond firm 0's commitment power if capacity-building is chosen, leaving outsourcing the only viable method of entry deterrence.

\footnotetext{
${ }^{10}$ Bagwell (1995) shows that if the incumbent's capacity is only observed by the entrant with some non-zero noise, the commitment value of capacity may totally vanish regardless of how small that noise is. Várdy (2004) finds that if observing the incumbent's capacity incurs some positive cost to the entrant, then the incumbent's commitment loses entirely its value, irrespective of the size of the observation cost.
} 


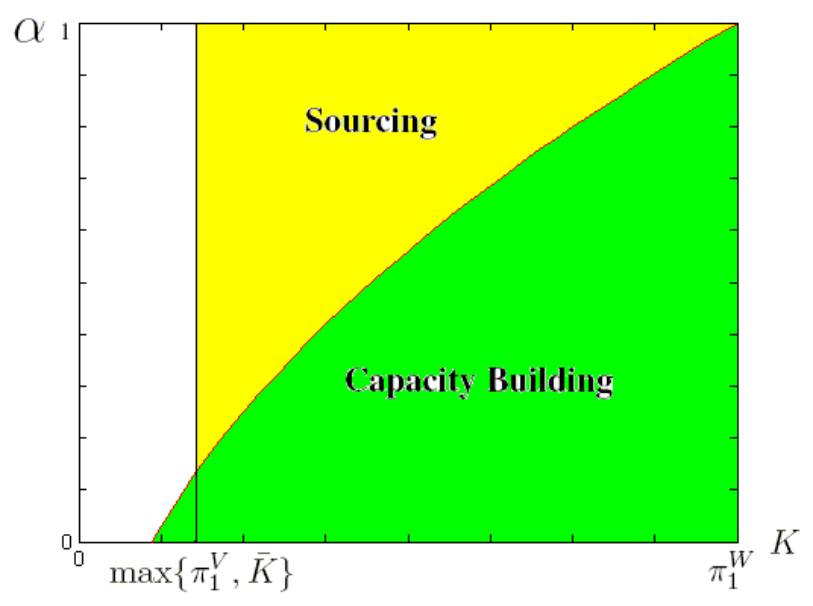

Figure 4: Sourcing vs. Capacity Building

\subsection{Pure Collusion}

Outsourcing leads to efficiency loss $\left(c_{1}>c_{0}\right)$ and in addition, excessive production of good $F$ when $\tau>q_{0}^{M}$. As these features of outsourcing leads to both firms' detriments, a pure collusion between firms 0 and 1 is appealing. However, if firm 0 does not outsource quantity $\tau$ of good $I$ to firm 1, a pure transfer payment from firm 0 to firm 1 can not forestall firm 1 from producing good $F$ : in stage two, firm 1 will always enter to reap its duopoly profit.

One may argue that firms could include a non-entry clause in their contract, so that firm 0 can be free of any obligations once firm 1 enters. Since $c_{1}>c_{0}$, firm 0 may order only a token amount from firm 1 if doing so help hiding the side payment hence can avoid catching attention of antitrust authorities. Nevertheless, such a collusive contract is not self-enforcing. Once firm 1 has stayed out, firm 0 lacks incentive to fulfill the side payment. While no outside authority will enforce the collusive contract, firm 1 shall enter instead of staying out for good $F$. Even if these two firms repeatedly interact in a dynamic setting, it is well-understood that pure collusion can be sustained in equilibrium only under certain circumstances. The merit of outsourcing in entry deterrence, therefore, in part relies with the fact that it survives backward induction and is self-enforcing.

\subsection{Model Variations}

We consider several model variations to gain insights on the robustness of our basic results. They include alternative pricing schemes in outsourcing, multiple potential entrants, price competition of good $F$, economies of scale in producing good $I$, and allowing firm 1 to outsource good $I$ to firm 0 .

Alternative Pricing Schemes. Our main result is well preserved with different pricing schemes in outsourcing such as linear pricing and two-part tariff. Here we only give analysis of the case when linear pricing is used. At the beginning of the game, let firm 1 announce price $p$ at which it is willing to supply good $I$, then firm 0 orders $x_{0}^{1}$. After that, stage two and stage three follow the same as in Game $\Gamma$. 
Consider the case when firm 1 enters. Since $p \geq c_{1}>c_{0},{ }^{11}$ firm 0 shall outsource only if by doing so it can obtain a Stackelberg leader's advantage in the future, implying that $x_{0}^{1}>q_{0}^{W}$. Foreseeing its loss as a Stackelberg follower by supplying firm 0 , firm 1 will set $p$ high enough so that it can recoup its loss as a follower in the market of good $F$. However, the upshot is, such a high price induces firm 0 to turn to in-house production, leading to no outsourcing in equilibrium. ${ }^{12}$ Thus Lemma 3 remains unaltered, meaning that the opportunity cost of entry deterrence to firm 1 is still $\pi_{1}^{W}-K$. From firm 0's aspect, at given $p$, its opportunity cost of entry deterrence is either $\pi_{0}^{W}$ (its profit at $x_{0}^{1}=0$ ), or its optimal profit when $x_{0}^{1} \in\left(q_{0}^{W}, \tau\right)$, the case when it lets firm 1 enter and then exploits its Stackelberg leader's advantage. Although the second case complicates our analysis to some extent, it has no effect on the qualitative part. Entry-deterring sourcing can again arise in SPNE, where firm 1 sets price $p$ of good $I$ in a way that firm 0 finds it optimal outsourcing $x_{0}^{1}=\tau$ to deter firm 1's entry.

Multiple Potential Entrants. Suppose firm 0 faces $n>1$ symmetric potential entrants, denoted as firms $1, \ldots, n$.

First, suppose these entrants appear in sequential periods. By ordering $x_{0}^{1}=\tau$ from firm 1 (suppose firm 1 is the first entrant to appear), firm 0 is able to deter all the entrants from producing good $F$. The other entrants, based on the observation that firm 0 outsources (they may not observe the exact outsourced quantity) and firm 1 chooses to stay out, understands that firm 0 has committed to a quantity large enough so that entry is no longer profitable.

Second, suppose these entrants appear at the same time and make simultaneous decisions whenever firm 1 moves in the baseline model. The solution concept to this game is sequential equilibrium. We find that, there exist multiple equilibria. In equilibrium, it can be that the incumbent accommodates all entrants, or it outsources to some of the entrants to deter their entry and let the rest enter. Nevertheless, the strategy stated in Theorem 1, combined with an appropriate belief system, constitutes a sequential equilibrium where all entrants stay out for good $F$. In this equilibrium, firm 0 outsources only to firm 1 quantity $\tau$. As a result, firm 1 will not enter for good $F$. Each of the other entrants, believing that there is outsourcing from firm 0 to firm 1 with quantity $\tau$, foresees that firm 0 's future quantity is no less than $\tau$ hence will not enter the market of good $F$. Moreover, none of firms 0 and 1 wants to deviate to $x_{0}^{1} \in[0, \tau)$, as that will invite firm 1's entry. In such an equilibrium, by outsourcing to firm 1 along, firm 0 is able to deter all the entrants from producing good $F$.

Bertrand Competition. Our major finding in the baseline model goes through the case when firms 0 and 1 produce differentiated good $F$ and compete in prices upon firm 1's entry. First, outsourcing $x_{0}^{1}>0$ before firm 1's entry still builds up a capacity for firm 0 , which is the key element to deter firm 1's entry. Producing within the established capacity

\footnotetext{
${ }^{11}$ Firm 1 has no incentive to set $p<c_{1}$. If it stays out, it loses money for each unit of good $I$ sold at a price lower than its average cost. If it enters, it may suffer as a Stackelberg follower in the market of good $F$ when supplying firm 0 , thus will never offer $p<c_{1}$ for good $I$.

${ }^{12}$ The case here when firm 1 enters is similar to the setting in Chen et al. (2009). In their setting, firm 0 can not produce good $I$ in-house. Instead, it chooses its supplier among pure outside suppliers and firm 1 , who is vertically integrated and is directly competing with firm 0 on good $F$. They find that, because firm 1 charges a high price of good $I$ in order to recoup its future loss as a Stackelberg follower, outsourcing from firm 0 to firm 1 occurs in equilibrium only if firm 1 is sufficiently more efficient than outside suppliers of good $I$. As in our setting firm 1 is less efficient, firm 0 shall never order from firm 1.
} 
again reduces firm 0 's marginal cost from $c_{0}$ to 0 when competing with firm 1 , leaving firm 0 a stronger incentive to cut its price for good $F$. Therefore, the outsourced quantity enables firm 0 to commit to a lower price for good $F$, which intensifies downstream competition and raises entry barrier. Second, the collusive effect of outsourcing persists. With firm 0 along producing good $F$, industry profit can exceed the joint autarky duopoly profit net of the entry cost, giving both firms incentive to sign the outsourcing contract. In fact, since price competition yields lower duopoly profit than quantity competition, the incentive for both firms to engage in entry-deterring outsourcing is even stronger under price competition.

Economies of Scale. If there are economies of scale in the production of good $I$, outsourcing from firm 0 to firm 1 strengthens firm 1's competency by reducing its average cost after entry, therefore may induce firm 1 to enter for good $F$. In light of this insight, we consider a modified game where firms' marginal cost of good $I$ is decreasing in quantity. Suppose market demand of good $F$ is $P(Q)=\max \{0, a-Q\}$. For simplicity, assume firm 0 and firm 1 are equally efficient with the production of good $I$, with cost function given by

$$
C(q)= \begin{cases}c q-v q^{2} & \text { for } q \leq \frac{c}{2 v} \\ \frac{c^{2}}{4 v} & \text { for } q>\frac{c}{2 v}\end{cases}
$$

which satisfies $C^{\prime}(q)>0, C^{\prime \prime}(q)<0$ for $q \leq \frac{c}{2 v}$. Assume $0<c<a \leq \frac{c}{2 v}$. The last inequality guarantees that production in equilibrium entails positive marginal cost. Moreover, cost function is not "too concave" so that the existence of post-entry Nash equilibrium is guaranteed. Everything else is kept the same as in the base setting.

We have two major findings to the modified game. First, in equilibrium, there exists a non-empty range of parameters where firm 0 sources to firm 1 for the purpose of deterring firm 1's entry. The main theme of our analysis to Game $\Gamma$ is unaltered. Second, in entry deterrence, firm 0 always fully outsources to firm 1 its demand of good $I$ and produces zero amount of good $I$ in-house. Clearly, such a deviation from our findings of Game $\Gamma$ is driven by firms' incentive to pursue scale economies.

Allowing Firm 1 to Outsource. In our baseline model, we rule out the possibility that firm 1 may outsource to firm 0 for good $I$. Clearly, firm 1 will never purchase good $I$ whenever it stays out for good $F$. However, when firm 1 is entering for good $F$, it may order good $I$ from firm 0 for efficiency gain. Moreover, there can be a second reason for such outsourcing, that is, to establish firm 1 as a Stackelberg leader in the market of good $F$.

We modify our baseline model in the following way. In stage one, firm 0 and firm 1 negotiate their transaction on good $I$ in terms of $\left\{x_{i}^{j}, S\right\}$, with $x_{i}^{j}$ the quantity of good $I$ supplied by firm $j$ to firm $i, i, j=0,1, i \neq j$, and $S$ the payment for the shipment of good $I$. Then stage two and stage three follow the same as in Game $\Gamma$, with $q_{0}, q_{1}$ in stage three subject to $q_{0} \leq x_{0}+x_{0}^{1}-x_{1}^{0} ; q_{1} \leq x_{1}+x_{1}^{0}-x_{0}^{1}$.

We find that, given that firm 1 enters for good $F$, in equilibrium firm 1 fully outsources its demand of good $I$ to firm 0 , and $x_{1}^{0}=q_{1}=q_{1}^{W}, x_{0}^{1}=0, q_{0}=q_{0}^{W}$. Each firm ends up producing the autarky duopoly quantity, implying that only efficiency gain can be achieved for firm 1 through its outsourcing. Allowing firm 1 to source to firm 0 thus increases the opportunity cost of entry deterrence from $\pi_{0}^{W}+\pi_{1}^{W}-K$ to $\left[P\left(Q^{W}\right)-c_{0}\right] Q^{W}-K$. Entrydeterring outsourcing from firm 0 to firm 1 still arises in SPNE, but is within a smaller range 
of parameters given by the following condition:

$$
\xi^{n}(K)>\left[P\left(Q^{W}\right)-c_{0}\right] Q^{W}-K .
$$

It can be shown that as long as $c_{1}<\tilde{c}_{1}$ where $\tilde{c}_{1} \in\left(c_{0}, \bar{c}_{1}\right)$, there exists a non-empty range of $K$ which satisfies Condition (7). In this range of $K$, firm 1 always enters without firm 0's outsourcing. However, in SPNE firm 0 outsources $x_{0}^{1}=\tau$ to have firm 1's entry deterred.

\section{Conclusion}

We examine the role of sourcing in entry deterrence in a setting where the potential entrant is able to provide key intermediate goods. We find that, incumbent of final good may order the intermediate good from the entrant for the sole purpose of preventing the latter from producing the final good. Two strategic effects exist with outsourcing. First, the outsourced amount commits to the incumbent's quantity of the final good, hence functions as an entrydeterring capacity of the incumbent. Second, an implicit collusion exists, where firms utilize outsourcing to keep the final-good market monopolized. These strategic elements can lead outsourcing to occur even when the entrant is costlier with the intermediate good production, as long as its cost disadvantage is not too severe.

We have exogenously assumed in our model a critical timing, namely, the quantity to outsource is determined before the entrant's entry decision. In fact, this timing can arise endogenously if we allow the entrant to choose either to make its entry decision prior to or following the incumbent's sourcing decision. It can be shown that, once outsourcing is negotiated after the entrant's entry, no outsourcing can occur and each firm ends up with its autarky duopoly profit. Therefore, whenever outsourcing arises in our base setting, it is the case that the entrant will choose to put off its entry decision until they finish the sourcing negotiation, so that it can benefit from entry deterrence.

Our model is readily extended to the case when a final-good producer lacks comparable ability in producing the intermediate good and is choosing among multiple suppliers. Our finding stresses that, an intermediate good supplier, by developing its entry potential for the final good, may acquire a competitive edge hence win the upstream competition. However, many factors are missing in our simple setting which could affect our major finding. To highlight the anticompetitive effect of sourcing of our central interests, we have ruled out the possibility that outsourcing is accompanied by technology leakage, which could directly build the entrant's entry potential. For example, the buyer may need to teach the seller related technique in order to guarantee high-quality supply. ${ }^{13}$ Besides, our finding is derived in a static setting. In a dynamic framework, an originally innocent supplier may gradually accumulate its technique know-how and innovate a superior final good through supplying the incumbent. However, it can also be the case that, repeated interaction between incumbent and entrant in the long run facilitates a higher degree of collusion, leading to even less entry. All these factors, including the technology leakage and the sustainability of long-run collusion through outsourcing, are interesting future research.

\footnotetext{
${ }^{13}$ Van Long (2005) analyzes a setting where outsourcing is associated with labor training in source country which can benefit rival firms. As a result, firms tend to retain part of their demand to inside production, irrespective of the high labor cost of internal sourcing.
} 


\section{Appendix}

Proof of Lemma 2. By Lemma 1, if $x_{0}^{1} \leq q_{0}^{W}$, firm 1 should enter for good $F$ since $\pi_{1}^{W}-K>0$; if $x_{0}^{1}>\min \left\{q_{0}^{V}, q_{0}^{R}\right\}$, firm 1 should stay out, otherwise it gets $\pi_{1}^{V}-K \leq 0$. For $x_{0}^{1} \in\left(q_{0}^{W}, \min \left\{q_{0}^{V}, q_{0}^{R}\right\}\right]$, by $(2)$ and $\pi_{1}^{f}\left(q_{0}^{W}\right)=\pi_{1}^{W}>K, \pi_{1}^{f}\left(q_{0}^{V}\right)=\pi_{1}^{V} \leq K$, there exists a unique intersection of $\pi_{1}^{f}\left(x_{0}^{1}\right)$ and $K$, given by $x_{0}^{1}=\tau(K)$, below which entry is profitable for firm 1. We have $\tau\left(\pi_{1}^{W}\right)=q_{0}^{W}, \tau\left(\pi_{1}^{V}\right)=\min \left\{q_{0}^{V}, q_{0}^{R}\right\}$, and $\tau(K) \in\left(q_{0}^{W}, \min \left\{q_{0}^{V}, q_{0}^{R}\right\}\right]$. By $\frac{d q_{1}^{b}\left(q_{1}\right)}{d q_{0}}<0$ and $q_{1}^{W}>0, q_{0}^{W}<q_{0}^{R}$ holds, hence $\left(q_{0}^{W}, \min \left\{q_{0}^{V}, q_{0}^{R}\right\}\right] \neq \varnothing$.

Proof of Lemma 3. Given firm 1's entry, if $x_{0}^{1}=0$, industry profit is $\pi_{0}^{W}+\pi_{1}^{W}-K$ by Lemma 1 and (3). Since either firm can opt out of outsourcing, $x_{0}^{1}>0$ can arise in equilibrium only if it leads to a joint surplus.

Suppose $x_{0}^{1}>0$. There can be three cases: (i) $x_{0}^{1} \in\left(0, q_{0}^{W}\right]$. By Lemma 1 and (3), industry profit is $\pi_{0}^{W}+\pi_{1}^{W}-K-\left(c_{1}-c_{0}\right) x_{0}^{1}<\pi_{0}^{W}+\pi_{1}^{W}-K$, a contradiction. (ii) $x_{0}^{1}>q_{0}^{V}$. Industry profit is $\pi_{0}^{V}+\pi_{1}^{V}-c_{1} x_{0}^{1}-K$. By deviating to $x_{0}^{1}=q_{0}^{V}$, industry profit can be improved to $\pi_{0}^{V}+\pi_{1}^{V}-c_{1} q_{0}^{V}-K$. At least one firm can be strictly better off with the other firm no worse off, again a contradiction. (iii) $x_{0}^{1} \in\left(q_{0}^{W}, q_{0}^{V}\right]$. For it to be in equilibrium, $\pi_{0}^{l}\left(x_{0}^{1}\right)+\pi_{1}^{f}\left(x_{0}^{1}\right)-c_{1} x_{0}^{1}>\pi_{0}^{W}+\pi_{1}^{W}$ must hold, implying $\left[P\left(x_{0}^{1}+q_{1}^{b}\left(x_{0}^{1}\right)\right)-c_{1}\right]\left(x_{0}^{1}+q_{1}^{b}\left(x_{0}^{1}\right)\right)>$ $\pi_{0}^{W}+\pi_{1}^{W}$. By (1), $x_{0}^{1}+q_{1}^{b}\left(x_{0}^{1}\right)>q_{0}^{W}+q_{1}^{b}\left(q_{0}^{W}\right)=q_{0}^{W}+q_{1}^{W}>0+q_{1}^{b}(0)=q_{1}^{M}$. By the strict concavity of profit, $\left[P\left(x_{0}^{1}+q_{1}^{b}\left(x_{0}^{1}\right)\right)-c_{1}\right]\left(x_{0}^{1}+q_{1}^{b}\left(x_{0}^{1}\right)\right)<\left[P\left(q_{0}^{W}+q_{1}^{W}\right)-c_{1}\right]\left(q_{0}^{W}+q_{1}^{W}\right)<\pi_{0}^{W}+\pi_{1}^{W}$, a contradiction. Thus must be $x_{0}^{1}=0$ whenever firm 1 enters. By Lemma 1 , profit is $\pi_{0}^{W}$ for firm 0 and $\pi_{1}^{W}-K$ for firm 1 .

Proof of Lemma 4. By Lemma 1, Lemma 2 and (4), to have firm 1 stays out, firms' problem in stage one is

$$
\begin{aligned}
& \max _{x_{0}^{1}} \xi^{n}\left(x_{0}^{1}\right)= \begin{cases}P\left(q_{0}^{M}\right) q_{0}^{M}-c_{1} x_{0}^{1}-c_{0}\left(q_{0}^{M}-x_{0}^{1}\right) & \text { if } x_{0}^{1}<q_{0}^{M} \\
P\left(x_{0}^{1}\right) x_{0}^{1}-c_{1} x_{0}^{1} & \text { if } x_{0}^{1} \in\left[q_{0}^{M}, q_{0}^{O}\right] \\
P\left(q_{0}^{O}\right) q_{0}^{O}-c_{1} x_{0}^{1} & \text { if } x_{0}^{1}>q_{0}^{O}\end{cases} \\
& \text { s.t. } x_{0}^{1} \geq \tau
\end{aligned}
$$

It is solved at $x_{0}^{1}=\tau$. Define $K^{M} \equiv \pi_{1}^{f}\left(q_{0}^{M}\right)$, then $\tau\left(K^{M}\right)=q_{0}^{M}$. By $(1), q_{0}^{R}=q_{0}^{R}+q_{1}^{b}\left(q_{0}^{R}\right)>$ $q_{0}^{W}+q_{1}^{W}>0+q_{0}^{b}(0)=q_{0}^{M}$. By $(2), \pi_{1}^{W}=\pi_{1}^{f}\left(q_{0}^{W}\right)>\pi_{1}^{f}\left(q_{0}^{M}\right)=K^{M}>\pi_{1}^{f}\left(q_{0}^{R}\right)=0$. I.e., $K^{M} \in\left(0, \pi_{1}^{W}\right)$. By $(5), \tau(K)<q_{0}^{M}$ when $K>K^{M}$. At $x_{0}^{1}=\tau(K)$, industry profit is

$$
\xi^{n}(\tau)= \begin{cases}\xi_{1}(\tau) \equiv P\left(q_{0}^{M}\right) q_{0}^{M}-c_{1} \tau-c_{0}\left(q_{0}^{M}-\tau\right) & \text { if } \quad K \geq K^{M} \\ \xi_{2}(\tau) \equiv P(\tau) \tau-c_{1} \tau & \text { if } K<K^{M}\end{cases}
$$

$\xi^{n}(\tau)$ is continuous in $K$ and kinked at $K=K^{M}$. By Lemma 3, outsourcing arises in equilibrium if and only if $\xi^{n}(\tau)>\Pi_{0}^{e}+\Pi_{1}^{e}$, rewritten as (6).

Proof of Lemma 5. First, we show that there exists a unique $\bar{K}$ such that (6) holds if and only if $K>\bar{K}$. We have

$$
\frac{d\left(\xi^{n}(\tau)+K\right)}{d K}= \begin{cases}\left(c_{0}-c_{1}\right) \frac{d \tau}{d K}+1 \geq 1 & \text { if } \quad K \geq K^{M} \\ \left(P^{\prime} \tau+P-c_{1}\right) \frac{d \tau}{d K}+1>1 & \text { if } \quad K<K^{M}\end{cases}
$$

The first inequality follows (5); the second inequality follows (5), the strict concavity of profit, and $\tau>q_{0}^{M}>q_{1}^{M}$ when $K<K^{M}$. Notice that $\pi_{0}^{W}+\pi_{1}^{W}$ does not vary in $K$. When $K=$ 
$\pi_{1}^{M}>K^{M}$, we have $\tau=0$ and $\xi^{n}(\tau)+K=P\left(q_{0}^{M}\right) q_{0}^{M}-c_{0} q_{0}^{M}+\pi_{1}^{M}=\pi_{0}^{M}+\pi_{1}^{M}>\pi_{0}^{W}+\pi_{1}^{W}$. When $K=0, \tau=q_{0}^{R}$ and $\xi^{n}(\tau)=\left[P\left(q_{0}^{R}\right)-c_{1}\right] q_{0}^{R}<\left[P\left(q_{0}^{W}+q_{1}^{W}\right)-c_{1}\right]\left(q_{0}^{W}+q_{1}^{W}\right)<\pi_{0}^{W}+\pi_{1}^{W}$. There exists a unique intersection of $\xi^{n}(\tau)$ and $\pi_{0}^{W}+\pi_{1}^{W}-K$, given by $\bar{K} \in\left(0, \pi_{1}^{M}\right)$. Condition (6) holds if and only if $K>\bar{K}$.

Second, we show the existence and uniqueness of $\bar{c}_{1}>c_{0}$. We start from showing that $\left(c_{1}-c_{0}\right) q_{0}^{W}+\pi_{0}^{W}-\pi_{0}^{M}$ is monotonic in $c_{1}$. Notice that $\left(q_{0}^{W}, q_{1}^{W}\right)$ are solutions to the two first order conditions:

$$
\begin{cases}P^{\prime} q_{0}+P-c_{0}=0 & F 1 \\ P^{\prime} q_{1}+P-c_{1}=0 & F 2\end{cases}
$$

By implicit function theorem,

$$
\frac{d q_{0}^{W}}{d c_{1}}=-\frac{P^{\prime \prime} q_{0}^{W}+P^{\prime}}{\left(P^{\prime}\right)^{2}+P^{\prime} P^{\prime \prime}\left(q_{0}^{W}+q_{1}^{W}\right)}>0, \frac{d q_{1}^{W}}{d c_{1}}=\frac{P^{\prime \prime} q_{0}^{W}+2 P^{\prime}}{\left(P^{\prime}\right)^{2}+P^{\prime} P^{\prime \prime}\left(q_{0}^{W}+q_{1}^{W}\right)}<0 .
$$

We have $\frac{d \pi_{0}^{W}}{d c_{1}}=\frac{\partial \pi_{0}^{W}}{\partial q_{1}} \frac{d q_{1}^{W}}{d c_{1}}+\frac{\partial \pi_{0}^{W}}{\partial c_{1}}=P^{\prime} q_{0}^{W} \frac{d q_{1}^{W}}{d c_{1}}>0$. Since $\pi_{0}^{M}$ is invariant in $c_{1}$ and

$$
\frac{d\left[\pi_{0}^{W}+\left(c_{1}-c_{0}\right) q_{0}^{W}\right]}{d c_{1}}=\frac{d \pi_{0}^{W}}{d c_{1}}+q_{0}^{W}+\left(c_{1}-c_{0}\right) \frac{d q_{0}^{W}}{d c_{1}}>0
$$

$\left(c_{1}-c_{0}\right) q_{0}^{W}+\pi_{0}^{W}-\pi_{0}^{M}$ is strictly increasing in $c_{1}$. When $c_{1}$ goes to its lower bound $c_{0}$, it goes to $\pi_{0}^{W}-\pi_{0}^{M}<0$. When $c_{1}$ goes to its upper-bound such that $q_{1}^{W}=0, q_{0}^{W}$ goes to $q_{0}^{M}$ and it goes to $\pi_{0}^{M}+\left(c_{1}-c_{0}\right) q_{0}^{M}-\pi_{0}^{M}>0$. A unique $\bar{c}_{1}>c_{0}$ exists such that $\left(\bar{c}_{1}-c_{0}\right) q_{0}^{W}+\pi_{0}^{W}-\pi_{0}^{M}=0$.

Third, at $c_{1}=\bar{c}_{1}$, it holds that $\bar{K}=\pi_{1}^{W}>K^{M}$. By the definition of $\bar{c}_{1}, P\left(q_{0}^{M}\right) q_{0}^{M}-$ $\bar{c}_{1} q_{0}^{W}-c_{0}\left(q_{0}^{M}-q_{0}^{W}\right)=\pi_{0}^{W}$. By the uniqueness of $\bar{K}$ at any given $c_{1}, \bar{K}=\pi_{1}^{W}$ at $c_{1}=\bar{c}_{1}$.

Finally, we prove that $\bar{K}<\pi_{1}^{W}$ if $c_{1}<\bar{c}_{1}$. Since $K^{M}<\pi_{1}^{W}$, when $\bar{K}$ is solved from $\xi_{2}(\tau)=\pi_{0}^{W}+\pi_{1}^{W}-K, \bar{K}<\pi_{1}^{W}$ is trivially satisfied. Consider the case when $\bar{K}$ is solved from $\xi_{1}(\tau)=\pi_{0}^{W}+\pi_{1}^{W}-K$. Define $f \equiv \xi_{1}(\tau)-\pi_{0}^{W}-\pi_{1}^{W}+K$. For $\bar{K} \geq K^{M}$, we have $\frac{d \bar{K}}{d c_{1}}=-\frac{d f / d c_{1}}{d f / d K}$. By (9), $\frac{d f}{d K}=\left(c_{0}-c_{1}\right) \frac{d \tau}{d K}+1>0$. Recall that $Q^{W} \equiv q_{0}^{W}+q_{1}^{W}$. It is true that $\frac{d Q^{W}}{d c_{1}}=\frac{1}{P^{\prime}+P^{\prime \prime} Q^{W}}<0$. Moreover, $\frac{d \pi_{1}^{W}}{d c_{1}}=\frac{\partial \pi_{1}^{W}}{\partial q_{0}} \frac{d q_{0}^{W}}{d c_{1}}+\frac{\partial \pi_{1}^{W}}{\partial c_{1}}=P^{\prime} q_{1}^{W} \frac{d q_{0}^{W}}{d c_{1}}-q_{1}^{W}<0$. Since $q_{0}^{W}>q_{1}^{W}$ and $\frac{d q_{1}^{W}}{d c_{1}}<0$, we have $\frac{d\left(\pi_{0}^{W}+\pi_{1}^{W}\right)}{d c_{1}}=P^{\prime} q_{0}^{W} \frac{d q_{1}^{W}}{d c_{1}}+P^{\prime} q_{1}^{W} \frac{d q_{0}^{W}}{d c_{1}}-q_{1}^{W}>P^{\prime} q_{1}^{W} \frac{d Q^{W}}{d c_{1}}-q_{1}^{W}$. Thus

$$
\begin{aligned}
& \frac{d f}{d c_{1}}=-\tau+\left(c_{0}-c_{1}\right) \frac{d \tau}{d c_{1}}-\frac{d\left(\pi_{0}^{W}+\pi_{1}^{W}\right)}{d c_{1}}<q_{1}^{W}-\tau+\left(c_{0}-c_{1}\right) \frac{d \tau}{d c_{1}}-P^{\prime}\left(Q^{W}\right) q_{1}^{W} \frac{d Q^{W}}{d c_{1}} \\
& \left.=q_{1}^{W}-\tau+\frac{P^{\prime}\left(Q^{W}\right)\left(q_{0}^{W}-q_{1}^{W}\right)}{P^{\prime}\left(\tau+q_{1}^{b}(\tau)\right)}-P^{\prime}\left(Q^{W}\right) q_{1}^{W} \frac{d Q^{W}}{d c_{1}} \quad \text { (by (5) and } F 1, F 2\right) \\
& \leq q_{1}^{W}-\tau+\left(q_{0}^{W}-q_{1}^{W}\right)-P^{\prime}\left(Q^{W}\right) q_{1}^{W} \frac{d Q^{W}}{d c_{1}} \quad\left(\text { as } \tau+q_{1}^{b}(\tau)>Q^{W}, \frac{P^{\prime}\left(Q^{W}\right)}{P^{\prime}\left(\tau+q_{1}^{b}(\tau)\right)} \in(0,1]\right) \\
& \left.=q_{0}^{W}-\tau-P^{\prime}\left(Q^{W}\right) q_{1}^{W} \frac{d Q^{W}}{d c_{1}}<0 . \quad \quad \text { (by Lemma } 2, \tau>q_{0}^{W}\right)
\end{aligned}
$$

Therefore $\frac{d \bar{K}}{d c_{1}}=-\frac{d f / d c_{1}}{d f / d K}>0$, proving $\bar{K}<\pi_{1}^{W}$ for $c_{1}<\bar{c}_{1}$.

Proof of Theorem 1. Proof of I. For $K \in \Psi$, Condition (6) holds and entry deterrence generates a joint surplus compared to the autarky case. In the market of good $I$, if firm 1 is just recouped its loss from staying out, $S=c_{1} x_{0}^{1}+\pi_{1}^{W}-K$; if firm 1 appropriates the whole 
surplus of entry deterrence, $S=\xi^{n}(\tau)-\left(\pi_{0}^{W}+\pi_{1}^{W}-K\right)$. For $S \in\left[c_{1} x_{0}^{1}+\pi_{1}^{W}-K, \xi^{n}(\tau)-\right.$ $\left(\pi_{0}^{W}+\pi_{1}^{W}-K\right)$ ], no firm has incentive to deviate to $x_{0}^{1}=0$. The rest part in I then follows Lemma 1-4.

Proof of II. Condition (6) is violated for $K \notin \Psi$. The rest part then follows Lemma 1 and Lemma 3.

Proof of Proposition 1. Notice that $\pi_{1}^{f}\left(Q^{W}\right)<\pi_{1}^{W}=\pi_{1}^{f}\left(q_{0}^{W}\right)$. Thus the condition for $\pi_{1}^{f}\left(Q^{W}\right) \in \Psi$ is (i) $\pi_{1}^{f}\left(Q^{W}\right) \geq \pi_{1}^{V}=\pi_{1}^{f}\left(q_{0}^{V}\right)$ and (ii) $\pi_{1}^{f}\left(Q^{W}\right)>\bar{K}$. By $(2)$, when $Q^{W} \leq q_{0}^{V}$, (i) is satisfied. Since $Q^{W}>q_{0}^{M}$, we have $\pi_{1}^{f}\left(Q^{W}\right)<K^{M}$ by (2). Moreover, $\tau\left(\pi_{1}^{f}\left(Q^{W}\right)\right)=Q^{W}$. By (9), if $P\left(Q^{W}\right) Q^{W}-c_{1} Q^{W}+\pi_{1}^{f}\left(Q^{W}\right)>\pi_{0}^{W}+\pi_{1}^{W}$, (ii) is satisfied. Reorganizing the inequality gives $\pi_{1}^{f}\left(Q^{W}\right)>\left(c_{1}-c_{0}\right) q_{0}^{W}$. It can be shown that $Q^{W}$ is decreasing in $c_{0}$; $\pi_{1}^{f}\left(Q^{W}\right)$ is increasing in $c_{0}$; and $\left(c_{1}-c_{0}\right) q_{0}^{W}$ is decreasing in $c_{0}$. Therefore, for $c_{0}$ relatively large, $\pi_{1}^{f}\left(Q^{W}\right)>\left(c_{1}-c_{0}\right) q_{0}^{W}$ holds; and $Q^{W}<q_{0}^{V}$ is also true since $q_{0}^{V}$ is invariant in $c_{0}$. Thus (i) and (ii) are satisfied and $\pi_{1}^{f}\left(Q^{W}\right) \in \Psi$.

\section{Acknowledgment}

I want to thank Sandro Brusco, Pradeep Dubey and Yossi Spiegel, for their suggestions and comments during the development of this work. I also want to thank Eva Carceles-Poveda, Yongmin Chen, Jianpei Li, Qihong Liu, Wallace Mullin, Debapriya Sen, Konstantinos Serfes, Yair Tauman, Na Yang and the audience in the 17th International Conference on Game Theory 2006, the 5th Annual International Industrial Organization Conference 2007, the 5th Biennial Conference of HKEA, for helpful discussions and comments.

\section{References}

Aghion, P., Bolton, P., 1987, Contracts as a Barrier to Entry. The American Economic Review, 77, 388-401.

Arya, A., Mittendorf, B. and Sappington, D., 2008a, Outsourcing, Vertical Integration, and Price vs. Quantity Competition. International Journal of Industrial Organization, 26, 1-16.

Arya, A., Mittendorf, B. and Sappington, D., 2008b, The Make-Or-Buy Decision in The Presence of a Rival: Strategic Outsourcing to a Common Supplier. Management Science, 54, 1747-1758.

Bagwell, K., 1995, Commitment and Observability in Games. Games and Economic Behavior, 8, 271-280.

Baake, P., Oechssler, J. and Schenk, C., 1999, Explaining Cross-Suppiles. Journal of Economics, 70, 37-60.

Bain, J., 1956, Barriers to New Competition. Cambridge, Mass.: Harvard University Press. Buehler, S. and Haucap, J., 2006, Strategic outsourcing revisited. Journal of Economic Behavior and Organization, 61, 325-338.

Caves, R., Porter, M., 1977, From Entry Barriers to Mobility Barriers: Conjectural Decisions and Contrived Deterrence to New Competition. The Quarterly Journal of Economics, 91, 241-262. 
Chen, Y., 2001, On Vertical Mergers and Their Competitive Effects. The Rand Journal of Economics, 32, 667-685.

Chen, Y., Ishikawa, J. and Yu, Z., 2004, Trade Liberalization and Strategic Outsourcing. Journal of International Economics, 63, 419-436.

Chen, Y., Dubey, P. and Sen, D., 2009, "Outsourcing Induced by Strategic Competition." working paper, Center for Game Theory in Economics, SUNY at Stony Brook.

Chen, Z., Ross, T., 2000, Strategic Alliances, Shared Facilities, and Entry Deterrence. The Rand Journal of Economics, 31, 326-344.

Dixit, A., 1979, A Model of Duopoly Suggesting a Theory of Entry Barriers. Bell Journal of Economics, 10, 20-32.

Dixit, A., 1980, The Role of Investment in Entry Deterrence. The Economics Journal, 90, 95-106.

Gelman, J., Salop, S., 1983, Judo Economics: Capacity Limitation and Coupon Competition. The Bell Journal of Economics, 14, 315-325.

Goolsbee, A., Syverson, C., 2008, How Do Incumbents Respond to The Threat of Entry? Evidence from The Major Airlines. The Quarterly Journal of Economics, 123, 1611-1633.

Hilke, J., 1984, Excess Capacity and Entry: Some Empirical Evidence. The Journal of Industrial Economics, 33, 233-240.

Judd, K., 1985, Credible Spacial Preemption. The Rand Journal of Economics, 16, 153-166. Lieberman, M., 1987, Excess Capacity As A Barrier to Entry: An Empirical Appraisal. The Journal of Industrial Economics, 35, 607-627.

Ordover, J., Saloner, G. and Salop, S., 1990, Equilibrium Vertical Foreclosure. The American Economic Review, 80, 127-142.

Rey, P. and Tirole, J., 2007, "A Primer on Vertical Foreclosure" in Handbook of Industrial Organization: Volume III, 2145-2220.

Salop, S., 1979, Strategic Entry Deterrence. The American Economic Review, 69, 335-338.

Salinger, M., 1988, Vertical Mergers and Market Foreclosure. Quarterly Journal of Economics, 103, 345-356.

Shy, O., Stenbacka, R., 2003, Strategic Outsourcing. Journal of Economic Behavior and Organization, 50, 203-224.

Shy, O., Stenbacka, R., 2005, Partial Outsourcing, Monitoring Cost, and Market Structure. Canadian Journal of Economics, 38, 1173-1190.

Spence, M., 1977, Entry, Investment and Oligopolistic Pricing. Bell Journal of Economics, $8,534-544$.

Spiegel, Y., 1993, Horizontal Subcontracting. The RAND Journal of Economics, 24, 570-590.

Smiley, R., 1988, Empirical Evidence on Strategic Entry Deterrence. International Journal of Industrial Organization, 6, 167-180.

Van Long, N., 2005, Outsourcing and Technology Spillovers. International Review of Economics and Finance, 14, 297-304.

Várdy, F., 2004, The Value of Commitment in Stackelberg Games with Observation Costs. Games and Economic Behavior, 49, 374-400. 